Research Article

\title{
The Pricing Decision and Channel Choice of Upgraded Products in the Presence of Strategic Consumers
}

\author{
Lingzhi Shao \\ School of Management Science and Engineering, Anhui University of Technology, Ma'anshan 243002, China \\ Correspondence should be addressed to Lingzhi Shao; shaolingzhi2005@126.com
}

Received 10 October 2020; Revised 25 November 2020; Accepted 14 December 2020; Published 13 January 2021

Academic Editor: Shilei Yang

Copyright ( 92021 Lingzhi Shao. This is an open access article distributed under the Creative Commons Attribution License, which permits unrestricted use, distribution, and reproduction in any medium, provided the original work is properly cited.

\begin{abstract}
Many dual-channel suppliers need to make appropriate strategies for their upgraded products in the presence of strategic consumers. This paper develops a two-period dynamic game framework to explore the optimal pricing and upgrade the channel choice when the supplier introduces new upgraded products to a market populated by strategic consumers. The results show that, under any upgrade channel choice, the strategic consumers' behavior has impacts on supplier and retailer's pricing decisions and reduces their profit. The supplier could choose appropriate upgrade channel to improve his performance according to the consumers' patience and innovation level of upgrade products. The supplier should choose pure offline channel to upgrade products when the innovation level of upgraded product $B$ is relatively small. With the sufficiently high innovation level, the supplier should adopt pure offline channel to upgrade products when consumers' patience is low and uses dual-channel upgrade strategy when the patience is high enough.
\end{abstract}

\section{Introduction}

With the developing of science and technology, to compete for market share and increase revenue, manufacturers and retailers in durable goods industries introduce new upgraded products continuously and phase out old products frequently. For example, a new mobile phone model is introduced into the market with innovative agenda, camera, or Internet functions every month. In the automobile industry, BMW for example constantly modifies its models to make them meaningfully different by regularly adding new features and capabilities so often. Similar patterns can be observed in other industries, including PCs, household appliances (e.g., washing machines, dryers, and vacuum cleaners), CRT devices (e.g., TV sets and monitors), and consumer electronics. Microsoft introduced 13 distinct versions of its Windows operation system over the last three decades. The incredible sales figures of Apple products, 156 million iOS devices in 2011, come from enhancing user experiences through incremental improvements.

Then, the product upgrade strategies are further complicated by several firm specific factors. Firms face uncertainty regarding whether a product launch will be successful, due to the relatively high occurrence of design, manufacturing, or supply chain problems [1]. And, how to make price and choose sale channel for the upgraded products and original products is an important issue that most manufactures need to be considered under the new retail background. First of all, the manufactures should decide to supply upgraded products through online, offline, or double channel. As Huawei's Internet brand, Honor has been focused on online channels since its independent operation in 2013 and regards offline channels as a kind of assistance and support. Therefore, the new upgraded products will be launched online and given priority to meet online needs. However, its competitors, such as OPPO, Vivo, and Jin li, pay more attention to the upgrading demand through off-line channel. Different from Honor, Huawei's Mate series products are mainly upgraded through offline channels before 2015 and through dual channels now. Other electronic products market will also show such phenomena; channel selection has become an important part of product upgrade strategy and an important mean for enterprises to improve profits. Secondly, the sellers need to set reasonable 
prices for upgraded and original products in different channels, taking into account channel differences and consumers' buying behaviors. For example, the innovating firms who upgrade their products frequently in several industries face the challenges of forward-looking consumers who anticipate product improvements and seek to delay their purchase. In the face of technology-driven product obsolescence, consumers may regret their prior purchases or agonize over current purchase timing decisions. In addition, as the boundaries between online and offline channels become increasingly blurred, the strategic consumers will make decisions of purchasing channels based on their own purchase benefits.

In this paper, we seek to study the price decisions and channel choice of the dual-channel supplier in the presence of strategic consumers. And, we also try to investigate the impact of some parameters, such as the degree of product upgrade, the patience of strategic consumers, and the difference of purchasing channels, on the upgrade strategy and revenue of firms. To address these questions, we consider a durable products market including a dual-channel supplier, a traditional retailer, and strategic consumers and present three classes of two-period dynamic models based on different upgrade channel choices including online upgrade, offline upgrade, and dual-channel upgrade, taking account of strategic behavior of forward-looking consumers. Solving the problems, we obtain the equilibrium price decisions under different upgrade channel choices and the conditions with which the certain upgrade channel choice helps improving the seller's profitability.

We find that it is better for the supplier to use offline upgrade strategy when the patience of strategic consumers is medium or relatively high which is related to the consumer value loss of online punchers compared with offline channel and the innovation incremental value of upgraded products. Otherwise, the supplier would choose dual-channel upgrade strategy. On the other hand, it could be found that the consumers' strategic behavior will affect the pricing decisions of enterprises under any upgrading strategy and the upgrading strategies of suppliers. The strategic behavior will decrease the firms' revenue in the supply chain.

The rest of paper is organized as follows. Section 2 reviews the related literature and explains our contributions in more detail. Section 3 outlines the key elements of our model, as well as the derivation of consumers purchase behavior. Section 4 describes the model framework, presents the optimal equilibrium solutions in different upgrade channels, and reports our main findings. Section 5 investigates the comparison of different upgrade strategies and the effect of factors using numerical experiments. Section 6 summarizes our conclusions and suggests opportunities for future research.

\section{Literature Review}

Our paper is closely related to the broader literatures on upgrade strategy in durable goods industry and operation management. Chung et al. [2] proposed a quantitative method based on dynamic programming to help upgrade planners and product users to find an optimal upgrade plan incorporating the forecasts for technology development and end-of-life decisions. Sale et al. [3] presented a model that simultaneously determines the optimal timing for the introduction of new product generations, pricing, production timing, and produced quantities. Chau and Desiraju [4] explored the relative optimality of five product-introduction strategies of a durable goods manufacturer: replacement, skipping, a delayed line, shelving, and line-extension. Kirshner et al. [5] advised that brand commitment and the risk of product failure play an important role in the timing of upgrades for a durable product. Sun et al. [6] developed two models that highlight the OEM's product upgrading strategy under two scenarios. Cui et al. [7] studied the effect of introducing a vertical differentiation strategy through sales of upgrades to a new type of premium product on the firm's price dispersion arising from its use of price discrimination for the base product. Shi and Shen [8] built up a newsvendor model with Bayesian information updating to examine whether the firm should adopt the product upgrading strategy. Liu et al. [9] examined the interaction between technology upgrade and a buyer entry in a supply chain and found that the buyer entry can increase the incumbent buyer's incentive to conduct the technology upgrade.

Then, our study is also related to the literatures on the consumers' strategic behavior, which has become a key factor that should be considered in operation management practice and research. Shum et al. [10] examined the impact of cost reduction under dynamic pricing, price commitment, and price matching strategies when selling to the strategic consumers. Yan and $\mathrm{Ke}$ [11] investigated two dynamic pricing strategies, namely, posterior price matching (PM) and delay posterior price matching (DPM) considering strategic consumer behavior. Chen and Farias [12] considered the canonical revenue management (RM) problem wherein a seller must sell an inventory of some product over a finite horizon via an anonymous, posted price mechanism, assuming that customers are forward looking. Moutaz et.al. [13] analyzed a newsvendor model in which the retailer can sell inventory to an off-price retailer and showed that selling to an off-price retailer can increase the retailer's profits and mitigate the negative effect of strategic consumer behavior.

And, some recent articles which perhaps are closer to ours have focused on the consumer strategic behavior related to product upgrade strategy. Liu et al. [14] developed a dynamic game framework to explore the optimal pricing strategy when the firm sequentially introduces new generations of products to a market populated by strategic consumers with trade-in option offered. Guo and Chen [15] developed an analytical model to study the effect of different purchase options by strategic consumers on a firm's profit and the firm's strategies for the timing and pricing of its successive generations of product diffusion. Hu et al. [16] proposed a game-theoretic analytical model to determine the optimal price of the next generation products and the optimal trade-in rebate, by considering the purchase behavior of both myopic consumers and strategic consumers. Sheu et.al [17] developed a framework where a high-tech firm sequentially introduces new products with incremental 
innovation over two selling seasons in the presence of strategic consumers and uncertain demand, to address the firm's optimal stocking and pricing decisions, and investigates how the key innovation features impact the firm's operational strategy and profit.

As mentioned above, most related literatures focus on the upgrading decisions of timing, stocking, and pricing of traditional single-channel suppliers. A few other articles focus on the competition between products and channels. Zhang et al. [18] built a game-theoretic model in which two competing manufacturers sell substitutable products (traditional and green upgraded products) through a common retailer. Zhang et al. [19] demonstrated the effectiveness of the proposed coordination mechanism in mitigating retail price competitions and enhancing the total profit of dualchannel closed-loop supply chains, compared to noncoordination models. Our paper differs from the extant literature in two ways: first, we focus on upgrade channel choices of multichannel supplier including online upgrade, offline upgrade, and dual-channel upgrade, considering the channel difference. Our results will present the equilibrium pricing decisions for the firms in different upgrade channel choices, and we try to help the supplier making choice between three upgrade channels. Secondly, we consider the setting where the consumers are strategic and will take the initiative to make purchase decisions such as delaying to buy or purchase channel transformation. Then, we try to understand the effect of consumers' strategic behavior on upgrade channel and pricing decision of the firms.

\section{Model Description}

3.1. The Firms' Problem. In the two-period model, the monopolistic supplier $(S)$ with continuous innovation sells product $A$ through retailer $(R)$ at price $p_{1 A}$ offline and through online channel at price $p_{1 \mathrm{OA}}$ in period 1 and supplies an upgraded version $B$ in period 2 . There are three upgrade strategies for S: dual-channel upgrade, offline upgrade, and online upgrade. The supplier $(S)$ follows dual-channel upgrade strategy, where $\mathrm{B}$ is available at price $p_{2 B}$ offline and at price $p_{2 \mathrm{OB}}$ online in period 2 , and $\mathrm{A}$ is not available in period 2. Under offline upgrade strategy, $B$ is available offline at price $p_{2 B}$, while $\mathrm{A}$ is provided online at price $p_{2 \mathrm{OA}}$ in period 2 . Under online upgrade strategy, $B$ is provided online at price $p_{2 \mathrm{OB}}$, while $\mathrm{A}$ is available offline at price $p_{2 A}$ in period 2 . Using dynamic pricing, the firms decide $p_{1 A}$ and $p_{1 \mathrm{OA}}$ in period 1 and $p_{2 B}, p_{2 \mathrm{OB}}, p_{2 \mathrm{OA}}$, and $p_{2 A}$ in period 2 . In the supply chain, the supplier $S$ and the retailer $R$ make pricing decisions in Stackelberg game at the beginning of each period. The wholesale price will be given by $S$ firstly, with the retail pricing decision being made by $R$ subsequently.

We assume that $\mathrm{A}$ and $\mathrm{B}$ are of the same marginal production cost, which is a common assumption for hightech products (Ray et al. [20]). Without loss of generality, we set the marginal cost to be zero (e.g., Bala and Carr [21]). The innovation level of $A$ and $B$ are 1 and $\beta(\beta>1)$, respectively, where the innovation incremental value of $B$ compared to $A$ is $(\beta-1)$. The supplier and retailer are risk-neutral, and their objective is to maximize the two-period total profit from two generations of products. To simplify the analysis, we assume that the firm has ample capacity to meet consumers' demand for both kinds of products, which is reasonable for software and electronics industries (Yin et al. [22]; Yin and Tang [23]). In dual-channel upgrade case, the supplier converts all production capacity into production of products $B$ and ensures that the demand is fully met. In the online or offline channel upgrade case, the supplier will convert part of the capacity into production of product $B$ and guarantee to fully meet the product demand of all channels. In addition, we also assume that the retailer's replenishment arrives instantaneously. These assumptions will help us to focus on the impact of different upgrade strategies.

3.2. The Consumer's Problem. All consumers arrive at the beginning of period 1 and period 2. Without loss of generality, we normalize the potential market size of each period to 1 . Consumers are heterogeneous in valuation. For new consumers in each period, the consumer's valuation of using $A$ is $v$, which follows a $[0,1]$ uniform distribution (Zhou et al. [24]). Due to the product's inexperience and waiting for delivery, we assume that the consumer's valuation for product A sold online is $\theta v(0<\theta<1)$. So, the consumer's valuation of $B$ depends on the innovation level of $B$ and the sale channel and may be expressed as $\beta v$ offline or $\theta \beta v$ online. We assume that the innovation level of upgraded products is large enough; even the upgraded products which are supplied online still have added innovation value, relative to the original products offline. So, there is $1<\theta \beta<\beta$.

Consumers arriving in period 1 make purchasing decisions of buying and using a product in this period immediately, waiting to buy an upgrade version in period 2 or leaving the market without buying and waiting, to maximize their two-period total surplus. The consumers' valuation of waiting and consuming the products in period 2 will be discounted by $\alpha(0 \leq \alpha \leq 1)$. Here, $\alpha$ captures not only the opportunity cost of postponed purchasing but also how strategic consumers are patient, i.e., $\alpha=0$ represents myopic consumers (Papanastasiou and Savva [25]; Shum et al. [10]). In our model, products are sold in only two periods, so the consumers in period 2 will make decisions of buying a product or leaving the market.

In this study, each consumer can purchase at most one unit of the same generation of product at any given time and no secondary market is available. We model a two-period dynamic game between the firms and a potential consumer with complete information, i.e., all of the parameters above are common knowledge, including the innovation incremental value of $B$ over $A$, the consumers' valuation loss of product online, how strategic consumers are, market size, and marginal production cost of both $A$ and $B$.

\section{Equilibrium Analysis under Different Upgrade Strategies}

In this section, we analyze the games among the supplier, retailer, and strategic consumers under dual-channel 
upgrade strategy, offline upgrade strategy (I, indirect), and online upgrade strategy $(\mathrm{D}$, direct).

4.1. Dual-Channel Upgrade Strategy. The sequence of events under dual-channel upgrade strategy is summarized in Figure 1. We assume that the rational consumers can develop an expectation of the prices in the second period according to their life experience and information released by enterprises, when they make purchase decisions in period 1. Before the period 1 starting, the supplier $S$ announces its upgrade strategy including the innovation level $\beta$ of product $B$ and his upgrade channel, and then $S$ and $R$ decide $p_{10 A}$, $w_{1 A}$, and $p_{1 A}$ in period 1 . The prices $\left(p_{2 \mathrm{OB}}, w_{2 B}\right.$, and $\left.p_{2 B}\right)$ in period 2 will be made and announced at the beginning of period.

The consumers arriving at the start of period 1 make purchase decisions according to supplier's upgrade strategy, price information of the period 1 , and their expectation of the prices in period 2. Here, we assume $\alpha \beta<\theta$. So, the strategic consumers in period 1 will not be patient to wait for buying the product $B$ offline in this paper. And, there are four choices for consumers in period 1: buy $A$ offline $(1 A)$, buy $A$ online (1OA), wait and buy $B$ online (WOB), and leave from the market $(1 N)$. Then, the choices for the consumers arriving in period 2 include buy $B$ offline $(2 B)$, buy $B$ online $(2 \mathrm{OB})$, and leave from the market $(2 N)$. We can describe the consumers' utility in different purchase choices as

$$
\begin{aligned}
u_{1 A} & =v-p_{1 A}, \\
u_{1 \mathrm{OA}} & =\theta v-p_{1 \mathrm{OA}}, \\
u_{\mathrm{WOB}} & =\alpha \theta \beta v-p_{2 \mathrm{OB}}, \\
u_{1 N} & =0, \\
u_{2 B} & =\beta v-p_{2 B}, \\
u_{2 \mathrm{OB}} & =\theta \beta v-p_{2 \mathrm{OB}}, \\
u_{2 N} & =0 .
\end{aligned}
$$

The consumers with higher utility will purchase earlier and choose the product with higher consumers' valuation. So, we can get the consumer distribution in period 1 as Figure 2 and in period 2 as Figure 3. In period 1, the consumers with valuation higher than the threshold will purchase $A$ offline, while the consumers with valuation between $V^{1 A, 1 O A}$ and $V^{1 \mathrm{OA}, \mathrm{WOB}}$ will purchase $A$ online. The consumers with valuation between $V^{1 \mathrm{OA}, \mathrm{WOB}}$ and $V^{\mathrm{WOB}, 1 N}$ will wait to buy $B$ online in period 2 . The other consumers with the less valuation will leave from the market. In period 2 , the consumers with the valuation higher than $V^{2 B, 2 \mathrm{OB}}$ will buy $B$, and the consumers with valuation less than $V^{2 \mathrm{OB}, 2 N}$ will leave from the market. The remaining consumers will buy product $B$ online.

The consumers with the valuation of $V^{1 A, 10 A}$ will be indifferent of buying $A$ offline and online. So, we can get the indifferent conditions as $V^{1 A, 1 \mathrm{OA}}=p_{1 A}-p_{1 \mathrm{OA}} /$ $1-\theta, V^{\mathrm{IOA}, \mathrm{WOB}}=p_{1 \mathrm{OA}}-p_{2 \mathrm{OB}} / \theta(1-\alpha \beta), \quad$ and $V^{\mathrm{WOB}, 1 N}=$ $p_{2 \mathrm{OB}} / \alpha \theta \beta$, solving the equation $V^{1 A, 1 \mathrm{OA}}-p_{1 A}=\theta V^{1 A, 1 \mathrm{OA}}-$ $p_{1 \mathrm{OA}}, \theta v-p_{1 \mathrm{OA}}=\alpha \theta \beta v-p_{2 \mathrm{OB}}$, and $\alpha \theta \beta v-p_{2 \mathrm{OB}}=0$. After formulating the consumers' second period indifferent conditions, we obtain the other thresholds as follows: $V^{2 B, 2 \mathrm{OB}}=p_{2 B}-p_{2 \mathrm{OB}} /(1-\theta) \beta, V^{2 \mathrm{OB}, 2 N}=p_{2 \mathrm{OB}} / \theta \beta$.

The proportion of products in two periods are as follows:

$\mathrm{Q}^{1 A}=1-\left(p_{1 A}-p_{1 \mathrm{OA}} / 1-\theta\right), \mathrm{Q}^{1 \mathrm{OA}}=\left(p_{1 A}-p_{1 \mathrm{OA}} / 1-\right.$ $\theta)-\left(p_{1 \mathrm{OA}}-p_{\mathrm{WOB}} / \theta(1-\alpha \beta)\right), \mathrm{Q}^{\mathrm{WOB}}=\left(p_{1 \mathrm{OA}}-p_{\mathrm{WOB}} / \theta(1-\right.$ $\alpha \beta))-\left(p_{\mathrm{WOB}} / \alpha \theta \beta\right), \quad Q^{2 B}=1-\left(p_{2 B}-p_{2 \mathrm{OB}} /(1-\theta) \beta\right)$, $Q^{2 O B}=\left(p_{2 B}-p_{2 \mathrm{OB}} /(1-\theta) \beta\right)-\left(p_{2 \mathrm{OB}} / \theta \beta\right)$, with the conditions of $0<V^{\mathrm{WOB}, 1 N} \leq V^{1 \mathrm{OA}, \mathrm{WOB}}<V^{1 \mathrm{~A}, 1 \mathrm{OA}}<1 \quad$ and $0<V^{2 \mathrm{OB}, 2 N}<V^{2 B, 2 \mathrm{OB}}<1$. This paper mainly studies the decision-making of a dual-channel supplier, considering that both online and offline channel always exist at the same time in two stages. Then, it excludes the case where $V^{1 \mathrm{OA}, \mathrm{WOB}}=V^{1 \mathrm{~A}, 1 \mathrm{OA}}$ and $V^{2 \mathrm{OB}, 2 N}=V^{2 B, 2 \mathrm{OB}}$ (the sales volume of online channel is zero).

We follow backward induction to obtain the subgame perfect equilibrium. Denote $\Pi_{2 R}$ and $\Pi_{2 S}$ as the retailer and supplier's second-period profit and $\Pi_{R}$ and $\Pi_{S}$ as the retailer and supplier's total profit in two periods. They could be described as

$$
\begin{aligned}
\Pi_{2 R} & =\left(p_{2 B}-w_{2 B}\right) Q^{2 B}, \\
\Pi_{2 S} & =w_{2 B} Q^{2 B}+p_{2 \mathrm{OB}}\left(Q^{2 \mathrm{OB}}+Q^{\mathrm{WOB}}\right), \\
\Pi_{R} & =\left(p_{1 A}-w_{1 A}\right) Q^{1 A}+\Pi_{2 R}^{*}, \\
\Pi_{S} & =w_{1 A} Q^{1 A}+p_{1 \mathrm{OA}} Q^{1 \mathrm{OA}}+\Pi_{2 S}^{*} .
\end{aligned}
$$

Then, their two-period pricing game model is formulated as

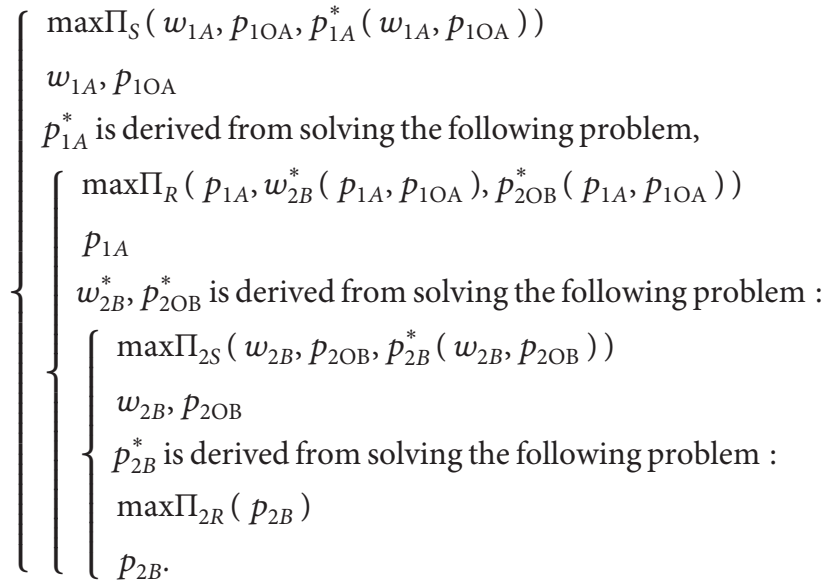

Solving the problem, we can get the Proposition 1 with the details in the Appendix A.

Proposition 1. Under dual-channel upgrade strategy, in the presence of strategic consumers, there exists a unique subgame perfect equilibrium (with determined parameters $\theta$ and $\beta$ ):

(1) When the consumers' patience ( $\alpha$ ) satisfies the condition, we get 


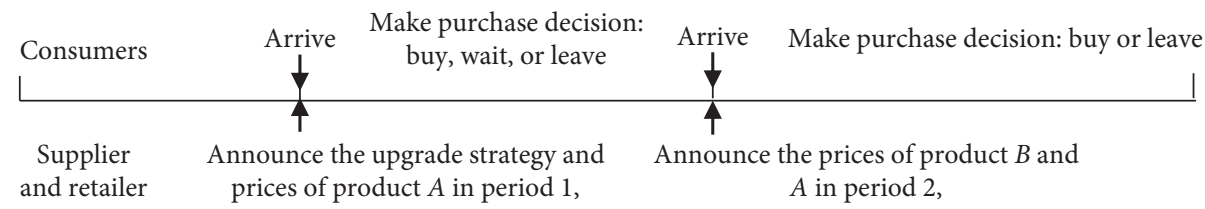

Figure 1: Sequence of events under dual-channel upgrade strategy.

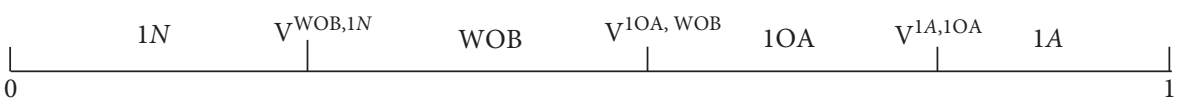

FIgURE 2: Consumer distribution in period 1.

\begin{tabular}{lcccc}
$2 N$ & $\mathrm{~V}^{2 \mathrm{OB}, 2 N}$ & $2 \mathrm{OB}$ & $\mathrm{V}^{2 B, 2 \mathrm{OB}}$ & $2 B$ \\
\hline & 1 & 1 & 1
\end{tabular}

FIgURE 3: Consumer distribution in period 2.

$$
\begin{aligned}
\frac{p_{2 \mathrm{OB}}^{*}}{\alpha \theta \beta}< & \frac{p_{1 \mathrm{OA}}^{*}-p_{2 \mathrm{OB}}^{*}}{\theta(1-\alpha \beta)}<\frac{p_{1 A}^{*}-p_{1 \mathrm{OA}}^{*}}{1-\theta}, \\
w_{1 A}^{*} & =\left(\frac{1-\theta}{2}\right)+p_{1 \mathrm{OA}}^{*}, \\
p_{1 A}^{*} & =\left(\frac{2(1-\theta)}{4}\right)+p_{1 \mathrm{OA}}^{*}, \\
p_{1 \mathrm{OA}}^{*} & =\left(\frac{16\left(1+\alpha-\alpha^{2} \beta\right)+4 \alpha \theta \beta(1-\alpha \beta)+10 \alpha \beta}{16\left(1+\alpha-\alpha^{2} \beta\right)-7 \alpha \theta \beta(1-\alpha \beta)-4 \alpha \beta}\right) \cdot\left(\frac{\theta(1-\alpha \beta)}{2}\right), \\
p_{2 \mathrm{OB}}^{*}= & \frac{\alpha \theta \beta(1-\alpha \beta)+2 \alpha \beta p_{1 \mathrm{OA}}^{*}}{4\left(1+\alpha-\alpha^{2} \beta\right)}, \\
w_{2 B}^{*}= & \frac{\alpha \theta \beta(1-\alpha \beta)+2(1-\theta) \beta+2 \alpha \beta p_{1 \mathrm{OA}}^{*}}{4\left(1+\alpha-\alpha^{2} \beta\right)} \\
p_{2 B}^{*}= & \frac{\left[2\left(1+\alpha-\alpha^{2} \beta\right)+1\right](1-\theta) \beta+\alpha \theta \beta(1-\alpha \beta)+2 \alpha \beta P_{1 \mathrm{OA}}^{*}}{4\left(1+\alpha-\alpha^{2} \beta\right)} .
\end{aligned}
$$

(2) Otherwise, $p_{1 O A}^{*}=\theta / 2, \quad w_{1 A}^{*}=1 / 2, \quad p_{1 A}^{*}=3-\theta / 4$, $p_{2 O B}^{*}=\theta \beta / 2, w_{2 B}^{*}=\beta / 2$, and $p_{2 B}^{*}=(3-\theta) \beta / 4$.

(3) The supplier $S$ will get more total profit, when the strategic consumers' patience satisfies the condition $p_{2 O B}^{*} / \alpha \theta \beta \geq p_{1 O A}^{*}-p_{2 O B}^{*} / \theta(1-\alpha \beta)$.

To get more information about the relationship between supplier's profit and consumers' patience, we can replicate some parameters, such as $\theta=0.9$ and $\beta=2$. Figure 4 could be obtained. When the consumers' patience is low and $0<\alpha<0.5$, the profit of suppler will be affected by $\alpha$. But, the profit will no longer change with the growth of patience, when $0.5<\alpha<1$. Then, the third part of Proposition 1 can be found intuitively in Figure 4.
With the numerical experiment, we can further get the relationship between price decisions, demand, and consumer patience (Figure 5 and 6). From the Figure 5, we see that the prices in period 1decrease in the consumers' patience $\alpha$ and the prices in period 2 increase in the patience within a certain range and then decreases with the increase of consumers' patience. With the increase of consumers' patience, firms can reduce the impact of consumers' strategic behavior by making prices dynamically (lowering the firststage prices and increasing the second stage prices) to encourage consumers to buy ahead of time. However, it is noted in Figure 6 that the amount of consumers who choose to wait for $B$ online in period 1 and total demand of $B$ online in period 2 increases with the patience. However, due to the 


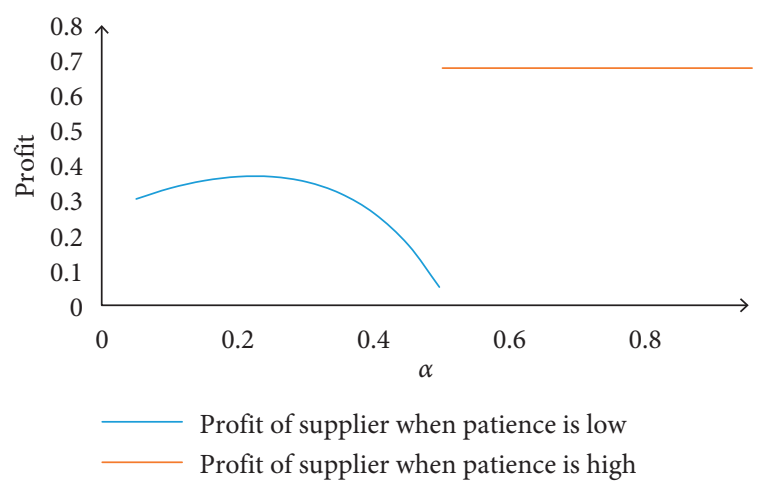

Figure 4: The profit of the supplier under dual channel.

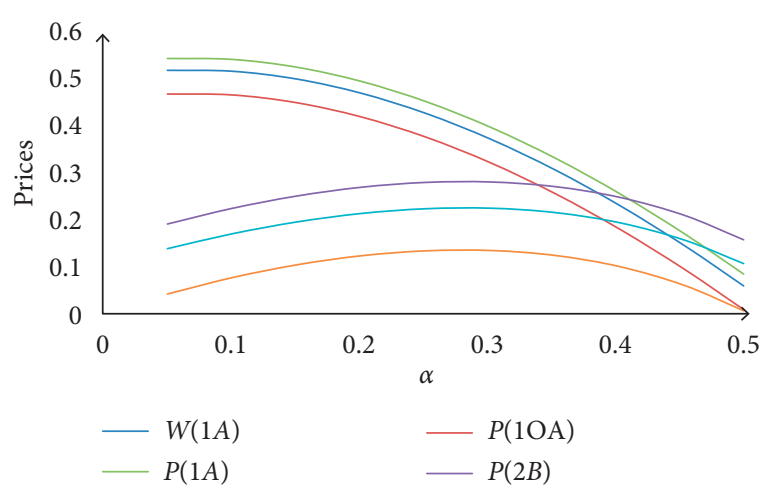

FIgURE 5: The prices under dual-channel upgrade strategy.

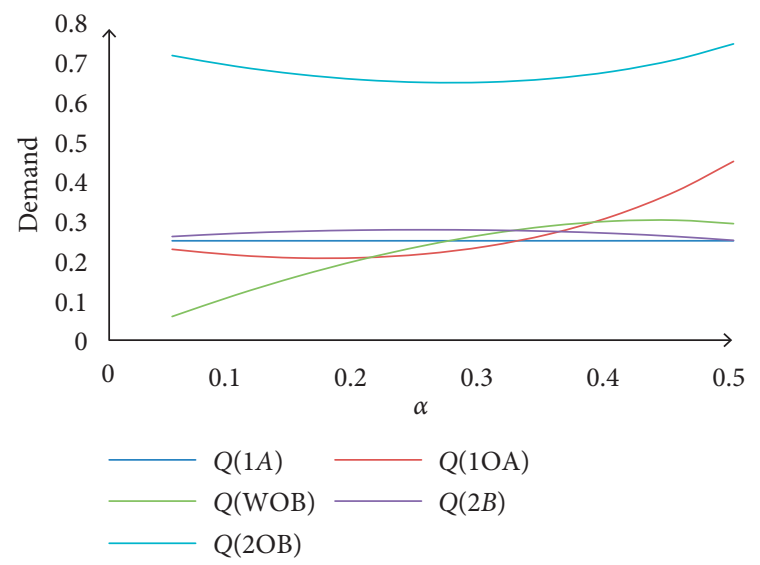

Figure 6: The demand under dual-channel upgrade.

relatively low online price of upgraded products in the second stage, consumers' waiting behavior will bring loss of profits to enterprises.

4.2. Off-Line Upgrade Strategy (I) and Online Upgrade Strategy $(D)$. The sequence of events under offline upgrade strategy is similar to Figure 1. The supplier and retailer announce the prices of products at the beginning of each period, and then the consumers make their purchase decisions. With the assumption $\alpha \beta<\theta$, there are also four choices for consumers arriving at the beginning of period 1: buy $A$ offline from retailer ( $1 A$ ), buy $A$ online (1OA), and wait and buy $A$ online (WOA) in period 2 (Usually, the price of product $A$ online in the second stage will be lower than that in the first stage; so, a portion of strategic consumers choose to wait for the price cuts) and leave from the market $(1 N)$. The choices for the consumers arriving in the period 2 include buy $B$ offline from retailer (2B), buy $A$ online (2OA), and leave from the market $(2 N)$.

The proportion of products in two periods are $Q^{I 1 A}=1-\left(p_{1 A}^{I}-p_{1 \mathrm{OA}}^{I} / 1-\theta\right), \quad Q^{I 2 B}=1-\left(p_{2 B}^{I}-p_{2 \mathrm{OA}}^{I} /\right.$ $\beta-\theta), Q^{I 1 \mathrm{OA}}=\left(p_{1 \mathrm{~A}}^{I}-p_{1 \mathrm{OA}}^{I} / 1-\theta\right)-\left(p_{1 \mathrm{OA}}^{I}-p_{2 \mathrm{OA}}^{I} / \theta(1-\right.$ $\alpha)), \quad Q^{\mathrm{IWOA}}=\left(p_{\mathrm{OAA}}^{I}-p_{2 \mathrm{OA}}^{I} / \theta(1-\alpha)\right)-\left(p_{2 \mathrm{OA}}^{I} / \alpha \theta\right)$, and $Q^{I 2 \mathrm{OA}}=\left(p_{2 B}^{I}-p_{2 \mathrm{OA}}^{I} / \beta-\theta\right)-\left(p_{2 \mathrm{OA}}^{I} / \theta\right)$, with the conditions of $0<V^{\mathrm{WOA}, 1 N} \leq V^{1 \mathrm{OA}, \mathrm{WOA}}<V^{1 A, 1 \mathrm{OA}}<1$ and $0<V^{2 \mathrm{OA}, 2 N}<$ $V^{2 B, 2 \mathrm{OA}}<1$.

Solving the two-stage price game model between firm and retailer, we can get the Proposition 2.

Proposition 2. Under offline upgrade strategy, in the presence of strategic consumers, there exists a unique subgame perfect equilibrium.

(1) When the consumers' patience is medium $(1 / 4<\alpha<3 / 4)$,

$$
\begin{aligned}
& p_{1 \mathrm{I}}^{I *}=2 \theta(1-\alpha)\left(1+2 \alpha-\alpha^{2}\right) / 4\left(1+\alpha-\alpha^{2}\right)-3 \alpha \\
& w_{1 A}^{I *}=(1-\theta / 2)+p_{1 \mathrm{OA}}^{I *}, p_{1 A}^{I *}=(3(1-\theta) / 4)+p_{1 \mathrm{OA}}^{I *}, \\
& p_{2 \mathrm{OA}}^{I *}=\alpha \theta(1-\alpha)+\alpha p_{1 \mathrm{OA}}^{I *} / 2\left(1+\alpha-\alpha^{2}\right) \\
& w_{2 B}^{I *}=\beta-\theta / 2+p_{2 \mathrm{OA}}^{I *}, \\
& \text { and } p_{2 B}^{*}=3(\beta-\theta) / 4+p_{2 \mathrm{OA}}^{I *}
\end{aligned}
$$

(2) Otherwise, $p_{1 \mathrm{OA}}^{*}=\theta / 2, \quad w_{1 A}^{I *}=1 / 2, \quad p_{1 A}^{I *}=3-\theta / 4$, $p_{2 \mathrm{OA}}^{I *}=\theta / 2, w_{2 B}^{I *}=\beta / 2$, and $p_{2 B}^{I *}=3 \beta-\theta / 4$.

(3) The supplier $S$ will get more total profit, when $0<\alpha<1 / 4$ or $3 / 4<\alpha<1$.

It is interesting to find that the retailer's profits in both periods are not affected by consumers' strategic behavior. Firstly, the unit profit of retailers in two periods are $(1-\theta) / 4$ and $(\beta-\theta) / 4$, respectively, and not affected by the consumers' strategic behavior. On the other hand, the demand of products offline has nothing to do with consumers' strategic behavior. So, consumers' strategic behavior mainly affects online sales and then affects supplier's performance, when their patience is medium.

It is different from the dual-channel upgrade strategy, the consumers in market with very low or very high patience will give up waiting for the price reduction in the second stage. Then, the supplier's and retailer's prices and profit which are the same with the situation without strategic consumers will not be affected by consumers' strategic behavior and be higher than that in the condition of high consumers' patience as described in Part 3 of Proposition 2. It can be shown in Figure 7 with the data experiments used in Proposition 1.

Under online upgrade strategy $(D)$, there are also four choices for consumers arriving at the beginning of period 1 : buy $A$ offline from retailer $(1 A)$, buy $A$ online (1OA), wait and buy $A$ offline (WA) in period 2, and leave from the market $(1 N)$. The choices for the consumers arriving in the beginning of period 2 include buy $A$ offline from retailer $(2 A)$, buy $B$ online $(2 \mathrm{OB})$, and leave from the market $(2 N)$. 




Figure 7: The profit of supplier under offline upgrade strategy.

The proportion of products in two periods $\operatorname{are}^{D 1 A}=1-\left(p_{1 A}^{D}-p_{1 \mathrm{OA}}^{D} / 1-\theta\right), \quad Q^{\mathrm{DWA}}=\left(p_{1 \mathrm{OA}}^{D}-p_{2 A}^{D} /\right.$ $\theta-\alpha)-\left(p_{2 A}^{D} / \alpha\right), \quad Q^{D 1 O A}=\left(p_{1 A}^{D}-\quad p_{1 \mathrm{OA}}^{D} / 1-\theta\right)-\left(p_{1 \mathrm{OA}}^{D}-\right.$ $\left.p_{2 A}^{D} / \theta-\alpha\right), \quad Q^{D 2 B}=1-\left(p_{2 \mathrm{OB}}^{D}-p_{2 A}^{D} / \theta \beta-1\right)$, and $Q^{D 2 A}=$ $\left(p_{2 \mathrm{OB}}^{D}-p_{2 A}^{D} / \theta \beta-1\right)-p_{2 A}^{D}$, with the conditions of $0<$ $V^{\mathrm{WA}, 1 N} \leq V^{1 \mathrm{OA}, \mathrm{WA}}<V^{1 A, 1 \mathrm{OA}}<1$ and $0<V^{2 A, 2 N}<V^{2 \mathrm{OB}, 2 A}$ $<1$.

Like the previous two upgrading strategies, we can construct the pricing game model between the supplier and retailer. Solving the model, it is found that there is no equilibrium solution under online upgrading strategy. But, if we change the above conditions of $0<V^{\mathrm{WA}, 1 N} \leq$ $V^{1 \mathrm{OA}, \mathrm{WA}}<V^{1 A, 1 \mathrm{OA}}<1$ and $0<V^{2 A, 2 N} \leq V^{2 \mathrm{OB}, 2 A}<1$, a unique subgame perfect equilibrium could be obtained. We can get Proposition 3.

Proposition 3. Under online upgrade strategy, in the presence of strategic consumers, if the abandonment of traditional sale channel is allowed, there exits a unique subgame perfect equilibrium: $\quad p_{1 O A}^{D *}=\theta / 2, \quad w_{1 A}^{D *}=1+\theta / 2, \quad p_{1 A}^{D *}=3 / 4$, $p_{2 A}^{D *}=1 / 2, w_{2 A}^{D *}=1 / 2$, and $p_{2 O B}^{D *}=\beta \theta / 2$, the supplier will sell upgrade products $B$ directly online and the retailer will withdraw from the supply chain; otherwise, there is no equilibrium.

This result is consistent with the reality that it is difficult for us to see dual-channel firms putting their upgraded products online for sale in the actual operation of enterprise product upgrading. Perhaps, one of the reasons for this phenomenon is the loss of product value due to unsatisfactory customer experience of online sales. Of course, this may be related to the dominance of suppliers in our model hypothesis. Under this assumption, the supplier $S$ gets most of the profits from the sales of products through traditional channels.

\section{Comparison of Different Upgrade Strategies}

With the equilibrium analyses above, we try to compare the dual-channel upgrade strategy and offline upgrade strategy in this section.

Firstly, the behavior of strategic consumers has different effects on firms' performance in different upgrading strategies. The relationship between price decisions and consumers' patience can be obtained as in Table 1. We assume that the consumers' patience meets the conditions of $p_{2 \mathrm{OB}}^{*} / \alpha \theta \beta<p_{2 \mathrm{OA}}^{*}-p_{2 \mathrm{OB}}^{*} / \theta(1-\alpha \beta)$ and $p_{2 \mathrm{OA}}^{I *} / \alpha \theta<\quad p_{1 \mathrm{OA}}^{I *}-$ $p_{2 \mathrm{OA}}^{I *} / \theta(1-\alpha)$, and then the consumers' patience will have effect on firms' decisions under two upgrade strategies. Under two strategies, the prices in the first period decreases with the patience of strategic consumers. This conclusion is similar to that of other studies on consumers' strategic behavior, and the main reason is that the firms facing the strategic consumers try to encourage consumers to buy in advance by lowering the first-stage pricing. But, under the dual-channel upgrading strategy, the prices in the second stage decrease with the increase of consumer patience while that increases with the consumers' patience under offline upgrade strategy.

On the other hand, from the numerical analysis and the figures (Figures 4 and 7), it can be found that the consumers' patience within a certain range has impact on supplier's profit and upgrade strategy. In order to understand these differences better, we firstly assume that consumers in the market are short-sighted and do not wait for buying behavior, and then the upgrading strategy choice of supplier $S$ will be different. When facing with short-sighted consumers, the equilibrium pricing decisions of supply chain under dual-channel upgrading strategy and offline upgrading strategy are shown in the second part of Proposition 1 and 2, respectively. The profit of supplier $S$ could be obtained as $\Pi_{S}^{\text {short }}=4 \theta-2+(1+\theta) \beta / 8$ under dual-channel upgrade strategy and $\Pi_{S}^{I \text {,short }}=1+2 \theta+\beta / 8$ under offline upgrade strategy. By comparison, there is $\Pi_{S}^{\text {short }}>\Pi_{S}^{I, \text { short }}$, when $\beta>3-2 \theta / \theta$. It means that the supplier $S$ should choose to upgrade his products $B$ in dual channel, when the innovation level of product $B$ is high enough. Otherwise, it is better for supplier to upgrade his product in offline channel.

Then, in the face of the influence of consumers' strategic behavior in the market, aiming at maximizing profits, the supplier $S$ should choose appropriate upgrading strategies considering the upgrade factor and consumers' patience. Comparing the profit of supplier that is $\Pi_{S}^{I *}$ under offline upgrade strategy when $p_{2 \mathrm{OA}}^{I *} / \alpha \theta<p_{1 \mathrm{OA}}^{I *}-p_{2 \mathrm{OA}}^{I *} / \theta(1-\alpha)$ and $\Pi_{S}^{*} \quad$ under offline upgrade strategy when $p_{2 \mathrm{OB}}^{*} /$ $\alpha \theta \beta<p_{1 \mathrm{OA}}^{*}-p_{2 \mathrm{OB}}^{*} / \theta(1-\alpha \beta)$, we can get that $\Pi_{S}^{*}<\Pi_{S}^{I *}$. In order to get a more intuitive conclusion, we use the previous numerical experiments $(\theta=0.9, \beta=2, \beta>(3-2 \theta) / \theta)$ and 
TABLE 1: The relationship between prices and consumer patience.

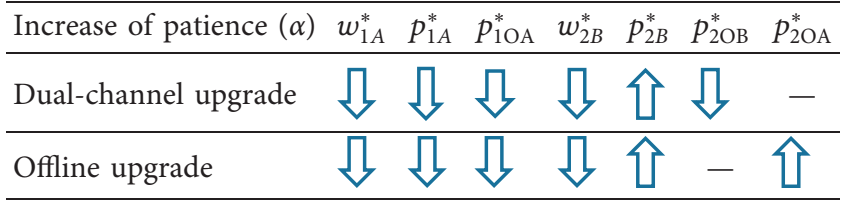

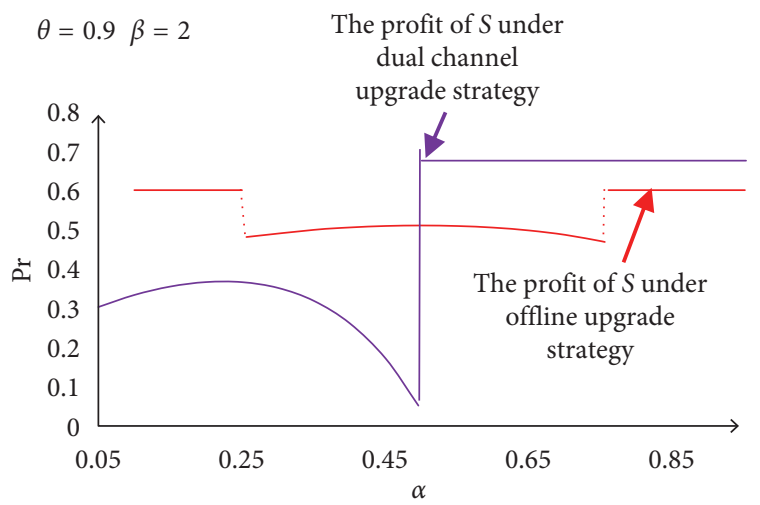

Figure 8: The profit of supplier under different upgrade strategies.

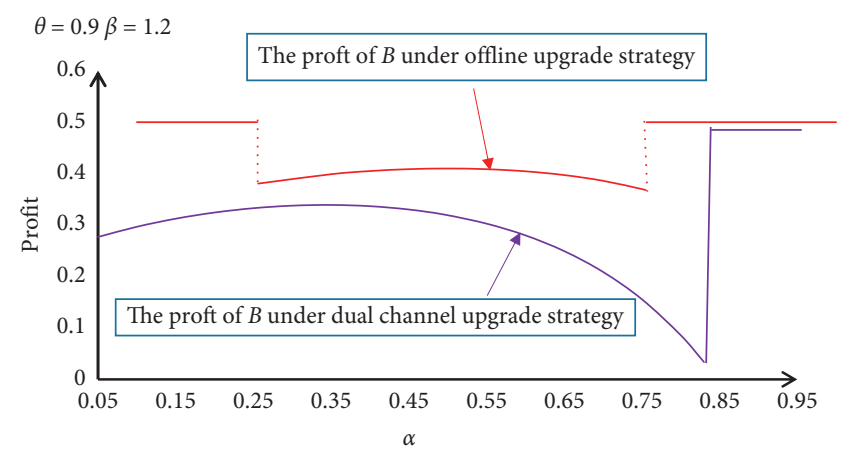

FIGURE 9: The profit of supplier under different upgrade strategies

$(\theta=0.9, \beta=1.2,1<\beta<(3-2 \theta) / \theta)$ to compare the total profit of supplier $S$ under different upgrade strategies and consumers' patience. Figures 8 and 9 can be obtained as follows.

From Figure 8, it can be found that when the consumers' patience is low, the supplier $S$ could get more profits in two periods using the offline upgrade strategy than dual-channel upgrade strategy. And, with the increase of consumers' patience, the dual-channel upgrading strategy shows more advantages when the patience is high enough $(\alpha>0.5$ in numerical experiments). Combining the equilibrium solutions under two upgrading strategies, we can draw the following proposition.

Proposition 4. Facing the strategic consumers in market, when $\beta>(3-2 \theta) / \theta$, the supplier S pursuing two-stage profit maximization should adopt pure offline channel to upgrade products when consumers' patience is low and adopt double channel upgrade strategy when patience is higher than the threshold $\left(\theta^{t}\right)$ which satisfies the condition $p_{2 O B}^{*} / \alpha \theta^{t} \beta<$ $p_{1 O A}^{*}-p_{2 O B}^{*} / \theta^{t}(1-\alpha \beta)$.

Then, we can draw the following proposition.

Proposition 5. Facing the strategic consumers in market, when $1<\beta<(3-2 \theta) / \theta$, the supplier $S$ pursuing two-stage profit maximization should adopt pure offline channel to upgrade products. Consumers' strategic behavior will not affect the supplier's upgrading strategy.

\section{Conclusion}

In this paper, we study the firms' price decisions and channel strategies for upgraded products taking account of the strategic consumer behavior. Our results are summarized as follows. Firstly, under the dual channel, off-line, and online upgrade strategies, the consumers' strategic behavior will affect the firms' pricing decisions and profits. The supplier $S$ and retailer $R$ will make different rational prices as consumer patience changes and they will reduce the price of the original product in the first period 1 to encourage strategic consumers to buy in advance. And then, the firms will get less profit when facing the strategic consumers. Under different pricing decisions of enterprises, the strategic consumers with different patience will adopt different purchasing behaviors. For example, a part of consumers arriving at market in period 1 chooses to wait for upgraded products until period 2 under dual-channel upgrade strategy, when the patience of consumers is low. While a part of the strategic consumers in period 1 with medium level of patience decide to delay purchase under offline upgrade strategy.

Second, the supplier $S$ can choose their product upgrading channel according to the patience of strategic consumers in the market and innovation level of upgrade product $B$ to improve his profits. The supplier $S$ should adopt pure offline channel to upgrade products when the innovation level of upgrade product $B$ is relatively small, and the consumer's strategic behavior will not affect supplier's upgrading strategy choice. With the increase of the innovation level, it should adopt pure offline channel to upgrade products when consumers' patience is low and doublechannel upgrade strategy when patience is high enough.

Third, the consumer's strategic behavior will change the supply chain structure under online upgrade strategy. When the supplier provides the upgrade products online in period 2 , the retailer gaining zero profit will withdraw from the supply chain in the equilibrium state. Then, the supplier will provide upgrade products $\mathrm{B}$ directly online and abandon original products and traditional sales channels.

So, the enterprises should fully consider the strategic purchasing behavior of consumers and try to use appropriate management leverage to reduce losses; otherwise, it will be possible to make unreasonable decisions and bring losses.

Certainly, there are several future research directions that might be explored in future research. First, aside from strategic consumers' patient, it would be valuable to examine the impact of the way of consumer's arrival and different distribution of strategic consumers on firms' profits and upgrade channel 
strategies. Second, we assume that the incremental innovation value of upgraded products over old versions is exogenous and determinant. However, the firm can decide the amount of investment in research and development (R\&D) in order to determine the innovation level. This direction is of concern in studying the interplay between investment decisions and rollover decisions. Third, our model is based on a two-period setting, which is common in the existing literature on strategic consumers and new product launching. It would be interesting to expand our model to a multiple-period setting, which is more realistic.

\section{Appendix}

\section{A. The proof of Proposition 1}

Considering the hypothesis in this paper that two sales channels (both online and offline) exist at the same time, the proportion of products in period 2 are $Q^{2 B}=1-$ $p_{2 B}-p_{2 \mathrm{OB}} /(1-\theta) \beta \quad$ and $\quad Q^{2 \mathrm{OB}}=\left(p_{2 B}-p_{2 \mathrm{OB}} /(1-\theta) \beta\right)-$ $\left(p_{2 \mathrm{OB}} / \theta \beta\right)$ with the conditions of $0<V^{2 \mathrm{OB}, 2 N}<V^{2 B, 2 \mathrm{OB}}<1$, $1<\theta \beta<\beta$ and $\alpha \beta<\theta$. However, there are two cases of product distribution in the first stage. Firstly, when $V^{1 \mathrm{OA}, \mathrm{WOB}}>V^{\mathrm{WOB}, 1 N} \Rightarrow p_{1 \mathrm{OA}}-p_{2 \mathrm{OB}} / \theta(1-\alpha \beta)>p_{2 \mathrm{OB}} / \alpha \theta \beta$, there is $Q^{1 A}=1-\left(p_{1 A}-p_{1 \mathrm{OA}} / 1-\theta\right), Q^{1 \mathrm{OA}}=\left(p_{1 A}-p_{1 \mathrm{OA}} /\right.$ $1-\theta)-\left(p_{1 \mathrm{OA}}-p_{\mathrm{WOB}} / \theta(1-\alpha \beta)\right), \quad \mathrm{Q}^{\mathrm{WOB}}=\left(p_{1 \mathrm{OA}}-\right.$ $\left.p_{\mathrm{WOB}} / \theta(1-\alpha \beta)\right)-\left(p_{\mathrm{WOB}} / \alpha \theta \beta\right)$. Secondly, when $V^{\mathrm{IOA}, \mathrm{WOB}}=V^{\mathrm{WOB}, 1 N} \Rightarrow p_{1 \mathrm{OA}}-p_{2 \mathrm{OB}} / \theta(1-\alpha \beta)=p_{2 \mathrm{OB}} / \alpha \theta \beta$, there is $Q^{1 A}=1-\left(p_{1 A}-p_{1 \mathrm{OA}} / 1-\theta\right), Q^{1 \mathrm{OA}}=\left(p_{1 A}-p_{1 \mathrm{OA}} /\right.$ $1-\theta)-\left(p_{1 \mathrm{OA}} / \theta\right)$ and $Q^{\mathrm{WOB}}=0$. So, we solve the game model in two cases.

(1) $p_{1 \mathrm{OA}}-p_{2 \mathrm{OB}} / \theta(1-\alpha \beta)>p_{2 \mathrm{OB}} / \alpha \theta \beta$

The demand of product $B$ in period 2 could be described as:

$$
\begin{aligned}
D^{2 B}= & 1-\left(\frac{p_{2 B}-p_{2 \mathrm{OB}}}{(1-\theta) \beta}\right) \\
D^{2 \mathrm{OB}}= & \left(\frac{p_{2 B}-p_{2 \mathrm{OB}}}{(1-\theta) \beta}\right)-\left(\frac{p_{2 \mathrm{OB}}}{\theta \beta}\right)-\left(\frac{\left(p_{1 \mathrm{OA}}-p_{\mathrm{WOB}}\right)}{\theta(1-\alpha \beta)}\right) \\
& -\left(\frac{p_{\mathrm{WOB}}}{\alpha \theta \beta}\right) .
\end{aligned}
$$

First of all, with the pricing decisions of firms in period 1 and the pricing decisions of supplier in period 2, the retailer makes pricing decision $p_{2 B}$ to maximize his profit in period 2. With the retailer's profit function $\Pi_{2 R}=\left(p_{2 B}-w_{2 B}\right) D^{2 B}$, solving the first-order condition, we can get the retailers' reaction function as $P_{2 B}=(1-\theta) \beta+P_{2 \mathrm{OB}}+W_{2 B} / 2$. It could be proved that $\partial \Pi_{2 R} / \partial P_{2 B}>0$ for all $P_{2 B}<(1-\theta) \beta+P_{2 \mathrm{OB}}+W_{2 B} / 2$ and $\partial \Pi_{2 R} / \partial P_{2 B}<0$ for all $P_{2 B}>(1-\theta) \beta+$ $P_{2 \mathrm{OB}}+W_{2 B} / 2$.

Considering the retailer's reaction, the supplier makes pricing decisions of $P_{2 \mathrm{OB}}, W_{2 B}$ to maximize his profit in period 2. Taking the retailer's reaction function into the supplier's profit function $\left(\Pi_{2 S}=P_{2 \mathrm{OB}}\left[\left(P_{1 \mathrm{OA}}-\right.\right.\right.$ $\left.P_{2 \mathrm{OB}} / \theta(1-\alpha \beta)\right)-\left(P_{2 \mathrm{OB}} / \alpha \theta \beta\right)+\left(P_{2 B}-P_{2 \mathrm{OB}} /(1-\theta) \beta\right)-$ $\left.\left.\left(P_{2 B} / \theta \beta\right)\right]+W_{2 B}\left[1-\left(P_{2 B}-P_{2 \mathrm{OB}} /(1-\theta) \beta\right)\right]\right)$, we can calculate that: $\partial \prod_{2 S}^{2} / \partial P_{2 \mathrm{OB}}^{2}<0, \quad \partial \prod_{2 S}^{2} / \partial W_{2 B}^{2}<0$, $\partial \prod_{2 S}^{2} / \partial P_{2 \mathrm{OB}} \partial W_{2 B}>0$ and $\partial \prod_{2 S}^{2} / \partial W_{2 B} \partial P_{2 \mathrm{OB}}>0$. The Hessian matrix $H=$ $\left(\begin{array}{cc}\partial \Pi_{2 S}^{2} / \partial P_{2 \mathrm{OB}}^{2} & \partial \Pi_{2 S}^{2} / \partial P_{2 \mathrm{OB}} \partial W_{2 B} \\ \partial \Pi_{2 S}^{2} / \partial W_{2 B} \partial P_{2 \mathrm{OB}} & \partial \Pi_{2 S}^{2} / \partial W_{2 B}^{2}\end{array}\right)>0 \quad$ which shows that the profit function is joint-concave and satisfy the second-order condition for a maximum. Solving the first-order conditions, we get the equations:

$$
\begin{aligned}
& P_{2 \mathrm{OB}}=\frac{\alpha \theta \beta(1-\alpha \beta)+2 \alpha \beta P_{1 \mathrm{OA}}}{4\left(1+\alpha-\alpha^{2} \beta\right)}, \\
& W_{2 B}=\frac{\alpha \theta \beta(1-\alpha \beta)+2(1-\theta) \beta+2 \alpha \beta P_{1 \mathrm{OA}}}{4\left(1+\alpha-\alpha^{2} \beta\right)},
\end{aligned}
$$

Then, coming to the problem in period 1, the supplier and retailer make pricing decisions to maximize their total profit in two periods with the national expectations for the second period. The demand of product $A$ in period 1 could be described as: $D^{1 A}=$ $1-\left(p_{1 A}-p_{1 \mathrm{OA}} / 1-\theta\right)$ and $D^{1 \mathrm{OA}}=\left(\left(p_{1 A}-p_{1 \mathrm{OA}} /\right.\right.$ $\left.1-\theta)-\left(p_{1 \mathrm{OA}}-p_{2 \mathrm{OB}} / \theta(1-\alpha \beta)\right)\right)$. Considering the reaction of firms in period 2 , the retailer makes decision firstly to maximize his total profits $\Pi_{R}=\left(p_{1 A}-W_{1 A}\right)\left(1-\left(p_{1 A}-p_{1 \mathrm{OA}} / 1-\theta\right)\right)+\Pi_{2 R}$. Solving the first-order condition, we can get the retailers' reaction function as $P_{1 A}=(1-\theta)+$ $P_{1 \mathrm{OA}}+W_{1 A} / 2$. Lastly, the supplier determines the prices to optimize his total two period profits $\Pi_{S}=$ $W_{1 A}\left(1-\left(p_{1 A}-p_{1 \mathrm{OA}} / 1-\theta\right)\right)+P_{1 \mathrm{OA}}\left(\left(p_{1 A}-p_{1 \mathrm{OA}} /\right.\right.$ $\left.1-\theta)-\left(p_{1 \mathrm{OA}}-p_{2 \mathrm{OB}} / \theta(1-\alpha \beta)\right)\right)+\Pi_{2 S}$. Solving the first-order conditions, we get the equations $p_{1 \mathrm{OA}}^{*}=$ $\left(16\left(1+\alpha-\alpha^{2} \beta\right)+4 \alpha \theta \beta(1-\alpha \beta)+10 \alpha \beta / 16(1+\alpha-\right.$ $\left.\left.\alpha^{2} \beta\right)-7 \alpha \theta \beta(1-\alpha \beta)-4 \alpha \beta\right) \cdot(\theta(1-\alpha \beta) / 2) \quad$ and $w_{1 A}^{*}=(1-\theta / 2)+p_{1 \mathrm{OA}}^{*}$. Then take the supplier's optimal prices $w_{1 A}^{*}$ and $p_{1 \mathrm{OA}}^{*}$ into the reaction functions of retailer and decisions of firms in period, we can get the first part of Proposition 1.

(2) $p_{1 \mathrm{OA}}-p_{2 \mathrm{OB}} / \theta(1-\alpha \beta)=p_{2 \mathrm{OB}} / \alpha \theta \beta$

In this case, there is $Q^{\mathrm{WOB}}=0$, and no consumer will wait for product $B$ online in period. The demand of product $A$ and $B$ in two periods could be described as:

$$
\begin{aligned}
D^{1 A} & =1-\left(\frac{p_{1 A}-p_{1 \mathrm{OA}}}{1-\theta}\right), \\
D^{1 O A} & =\left(\frac{p_{1 A}-p_{1 \mathrm{OA}}}{1-\theta}\right)-\left(\frac{p_{1 \mathrm{OA}}}{\theta}\right), \\
D^{2 B} & =1-\left(\frac{p_{2 B}-p_{2 \mathrm{OB}}}{(1-\theta) \beta}\right), \\
D^{2 O B} & =\left(\frac{p_{2 B}-p_{2 \mathrm{OB}}}{(1-\theta) \beta}\right)-\left(\frac{p_{2 \mathrm{OA}}}{\theta}\right) .
\end{aligned}
$$


Similarly, using the standard backward deduction method, we can solve the pricing games and obtain the optimal equilibrium prices of firms as the second part of Proposition 1.

\section{Data Availability}

No data were used to support this study.

\section{Conflicts of Interest}

The authors declare that they have no conflicts of interest.

\section{Acknowledgments}

This work was supported by the National Natural Science Foundation of China (NSFC) (Grant no. 71801004).

\section{References}

[1] A. M. Fernandes and C. Paunov, "The risks of innovation: are innovating firms less likely to die?" Social Science Electronic Publishing, vol. 97, no. 3, pp. 638-653, 2012.

[2] W.-H. Chung, G. E. O. Kremer, and R. A. Wysk, "A dynamic programming method for product upgrade planning incorporating technology development and end-of-life decisions," Journal of Industrial and Production Engineering, vol. 34, no. 1, pp. 30-41, 2017.

[3] R. S. Sale, H. I. Mesak, and R. A. Inman, "A dynamic marketing-operations interface model of new product updates," European Journal of Operational Research, vol. 257, no. 1, pp. 233-242, 2017.

[4] N. N. Chau and R. Desiraju, "Product introduction strategies under sequential innovation for durable goods with network effects," Production and Operations Management, vol. 26, no. 2, pp. 320-340, 2017.

[5] S. N. Kirshner, Y. Levin, and M. Nediak, "Product upgrades with stochastic technology advancement, product failure, and brand commitment," Production and Operations Management, vol. 26, no. 4, pp. 742-756, 2017.

[6] L. Sun, L. Zhang, and Y. Li, "Sustainable decisions on product upgrade confrontations with remanufacturing operations," Sustainability, vol. 10, no. 11, 4090 pages, 2018.

[7] Y. Cui, A. Y. Orhun, and I. Duenyas, "How price dispersion changes when upgrades are introduced: theory and empirical evidence from the airline industry," Management Science, vol. 65, no. 8, pp. 3470-3469, 2019.

[8] X. Shi and B. Shen, "Product upgrading or not: R\&D tax credit, consumer switch and information updating," International Journal of Production Economics, vol. 213, pp. 13-22, 2019.

[9] G. Liu, X. Shao, and X. Lang, "On the interaction of technology upgrade and buyer entry in a supply chain," International Journal of Production Economics, vol. 221, no. 10 , pp. $7478,2020$.

[10] S. Shum, S. Tong, and T. Xiao, "On the impact of uncertain cost reduction when selling to strategic customers," Management Science, vol. 63, no. 3, pp. 843-860, 2017.

[11] B. Yan and C. Ke, "Two strategies for dynamic perishable product pricing to consider in strategic consumer behaviour," International Journal of Production Research, vol. 56, no. 5, pp. 1757-1772, 2018.
[12] Y. Chen and V. F. Farias, "Robust dynamic pricing with strategic customers," Mathematics of Operations Research, vol. 43, no. 4, pp. 1119-1142, 2018.

[13] K. Moutaz, X. Liu, and J. Zhou, "To sell or not to sell to an offprice retailer in the presence of strategic consumers," Omega, vol. 90, no. 10, pp. 1-17, 2020.

[14] J. Liu, X. Zhai, and L. Chen, "Optimal pricing strategy under trade-in program in the presence of strategic consumers," Omega, Article ID S0305048317309970, 2018.

[15] Z. Guo and J. Chen, "Multigeneration product diffusion in the presence of strategic consumers," Information Systems Research, vol. 29, no. 1, pp. 206-224, 2018.

[16] S. Hu, Z.-J. Ma, and J.-B. Sheu, "Optimal prices and trade-in rebates for successive-generation products with strategic consumers and limited trade-in duration," Transportation Research Part E: Logistics and Transportation Review, vol. 124, pp. 92-107, 2019.

[17] Z. Sheu, W. Qi, T. Gong, L. Chen, and Z.-J. M. Shen, "Innovation uncertainty, new product press timing and strategic consumers," Omega, vol. 89, pp. 122-135, 2019.

[18] X. Zhang, Y. Jin, and C. Shen, "Manufacturers' green investment in a competitive market with a common retailer," Journal of Cleaner Production, vol. 276, Article ID 123164, 2020.

[19] Z. Zhang, S. Liu, and B. Niu, "Coordination mechanism of dual-channel closed-loop supply chains considering product quality and return," Journal of Cleaner Production, vol. 248, Article ID 119273, 2020.

[20] S. Ray, T. Boyaci, and N. Aras, "Optimal prices and trade-in rebates for durable, remanufacturable products," Manufacturing \& Service Operations Management, vol. 7, no. 3, pp. 208-228, 2005.

[21] R. Bala and S. Carr, "Pricing software upgrades: the role of product improvement and user costs," Production and $O P$ erations Management, vol. 18, no. 5, pp. 560-580, 2009.

[22] R. Yin, H. Li, and C. S. Tang, "Optimal pricing of two successive-generation products with trade-in options under uncertainty," Decision Sciences, vol. 46, no. 3, pp. 565-595, 2015.

[23] R. Yin and C. S. Tang, "Optimal temporal customer purchasing decisions under trade-in programs with up-front fees," Decision Sciences, vol. 45, no. 3, pp. 373-400, 2014.

[24] E. Zhou, J. Zhang, Q. Gou, and L. Liang, "A two period pricing model for new fashion style launching strategy," International Journal of Production Economics, vol. 160, no. 2015, pp. 144-156, 2015.

[25] Y. Papanastasiou and N. Savva, "Dynamic pricing in the presence of social learning and strategic consumers," Management Science, vol. 63, no. 4, pp. 919-939, 2016. 